\title{
Mental and Physical Health and Hygienic, Nutritional and Daily Habits during Quarantine in COVID-19 Pandemic
}

\author{
Carol Dillon ${ }^{1,2}{ }^{*}$, Patricio Perez Leguizamon ${ }^{1,3}$, Diego Castro ${ }^{1,3}$, Veronica Guelar ${ }^{1}$, Virginia Garcia ${ }^{1}$, \\ Monica Feldman', Adriana Leis ${ }^{1}$, Marina Romano ${ }^{3}$, Cecilia Peralta ${ }^{3}$, Juan Ignacio Rojas ${ }^{3}$, \\ Silvana Maggi ${ }^{3}$, María Belen Viaggio ${ }^{3}$ \\ ${ }^{1}$ Área de Neuropsiquiatría y Neurología Cognitiva, Sección de Neurología, Departamento de Medicina, Hospital Universitario \\ CEMIC, Buenos Aires, Argentina \\ ${ }^{2}$ Consejo Nacional de Investigaciones Científicas y Técnicas (CONICET), Facultad de Ciencias Sociales, Universidad de Palermo, \\ Buenos Aires, Argentina \\ ${ }^{3}$ Sección de Neurología, Departamento de Medicina, Hospital Universitario CEMIC, Buenos Aires, Argentina \\ Email: ^drcaroldillon@gmail.com
}

How to cite this paper: Dillon, C., Leguizamon, P.P., Castro, D., Guelar, V., Garcia, V., Feldman, M., Leis, A., Romano, M., Peralta, C., Rojas, J.I., Maggi, S. and Viaggio, M.B. (2020) Mental and Physical Health and Hygienic, Nutritional and Daily Habits during Quarantine in COVID-19 Pandemic. Open Access Library Journal, 7: e6934.

https://doi.org/10.4236/oalib.1106934

Received: October 26, 2020

Accepted: November 24, 2020

Published: November 27, 2020

Copyright $\odot 2020$ by author(s) and Open Access Library Inc.

This work is licensed under the Creative Commons Attribution International License (CC BY 4.0).

http://creativecommons.org/licenses/by/4.0/ (c) (i) Open Access

\begin{abstract}
Introduction: The outbreak of the new coronavirus (COVID-19) was declared as a pandemic by the World Health Organization in March 2020. The Argentinian government adopted a preventive social isolation and lockdown strategy as an exceptional measure in this critical world context. This lockdown strategy has kept a large number of people in isolation and affected many aspects of people's lives. Objective: To describe the physical and mental health status and possible changes in hygienic, nutritional and, daily habits during quarantine in the COVID-19 pandemic. Materials and Method: An online anonymous survey was sent to the general population of Buenos Aires city, 434 people answered the questionnaire. Results: Fifty-one percent of respondents were between 40 and 70 years old. Most respondents were female (75.8\%) and had higher education (62.2\%). Thirty point eight percent had a pre-existing disease and in $50.7 \%$ of these cases, the usual symptoms experienced by respondents remained unchanged. The onsets of anxiety $(38.2 \%)$, depression symptoms (27.9\%), sleep disorders (20.5\%), and irritability (27.2\%) were reported during the isolation period. Also, changes in eating habits $(55.5 \%)$ were reported. Significant improvement was reported in personal hygiene $(80.2 \%)$ and home cleaning $(81.3 \%)$ habits. It was also observed that despite the isolation some people continued doing physical activity. Conclusions: Respondents did not report significant changes in the symptoms of their preexisting diseases and had a positive mindset towards personal hygiene and home cleaning. Also, reported continuity in physical activity
\end{abstract}


during isolation. However, the onset of psychiatric symptoms such as anxiety, depression, irritability and sleep problems, and, changes in eating habits were observed during the quarantine.

\section{Subject Areas}

Epidemiology, Psychology

\section{Keywords}

COVID-19 Pandemic, Survey, Physical Health, Mental Health, Daily Habits, Quarantine

\section{Introduction}

The Coronavirus Disease 2019 (COVID-19) epidemic outbroke in Wuhan, China, spread nationwide, and then onto half a dozen other countries between December 2019 and early 2020 [1]. On March 11th, 2020, the World Health Organization declared the outbreak of the new coronavirus (COVID-19) as a pandemic.

In South America, the first case was a 61-year-old Brazilian man who had been in Lombardy, Northern Italy; from February 9th to 20th, 2020; where a significant outbreak was ongoing and upon arriving in Sao Paulo was confirmed positive on February 21st, 2020 [2] [3]. Later, on March 1st, 2020 Argentina confirmed the first case of Covid-19 in a 43-year-old man, who had also visited Italy [4].

The social, preventive, and compulsory isolation (referred hereafter as SPCI) was an exceptional measure that the Argentinian government adopted in a critical world context. It was imposed on March 20th, 2020 (4). To protect public health against the spread of the new coronavirus, it was defined that all inhabitants and visitors should remain in their places of residence or temporary accommodations and would only be able to make the fewest essential outings to stock up on cleaning supplies, medicines, and food.

The implementation of unprecedented strict quarantine measures has kept a large number of people in isolation and affected many aspects of people's lives.

This abrupt but necessary change in people's life due to quarantine probably had an impact on the everyday life activities of the population. Many people could not go to work and some turned to home working, children could not go to school and online education was rapidly implemented, all these factors tend to change the home environment. In the stricter lockdown period, people could not practice physical exercise outdoors as they used to do.

Information about COVID-19 positive cases, deaths, and in-patients was daily informed on radio, TV, internet. Changes in hygienic habits were promoted by all means.

As regards medical assistance, surgeries, clinical controls, screening practices, 
and other medical activities were suspended or decreased. Hospital activities were concentrated on treating and making the diagnosis of COVID-19 cases.

All these factors have triggered, in other countries, a wide variety of psychological problems, such as panic disorder, anxiety, and depression [1]. Different research studies [1] [5] [6] [7] [8] have described anxiety, depression, and other mental health problems during the COVID-19 pandemic.

During this pandemic situation, it was intended to contact patients and people from the general population to inform them if any medical problem needed to be addressed, or, if there was a change in their lifestyle that could affect them in the future, such as the onset of anxiety, depression or distress symptoms. Or else, changes in their daily habits such as lack of exercise, sedentary lifestyle, increase in cigarette smoking, or, eating disorders that could be triggered by this stressful event.

Our research interest and hypothesis was that this pandemic situation and the SPCI could have an impact on the mental and physical health of the population and also could have generated changes in everyday life activities and habits such as eating habits, physical activity, and home cleaning.

The present study aimed to observe and describe the physical and mental health status of the respondents, and the presence of changes in hygiene, food, and lifestyle habits during the SPCI period in the population of the city of Buenos Aires.

\section{Materials and Methods}

A cross-sectional study was performed. An anonymous, voluntary web-based survey was designed to investigate hygienic and nutritional habits, physical status, and mental health of the general population. The study was performed as descriptive research. The sampling frame included individuals equal to or over 18 years living in the Autonomous City of Buenos Aires A non-probability voluntary response sample was chosen from a larger population [9]. The population studied was the inhabitants of Buenos Aires city. The Autonomous City of Buenos Aires (CABA) is one of the twenty-four federal entities and capital of the Argentine Republic. It is located in the central-eastern region of the country [10]. Buenos Aires city has an estimated population of 3,075,646 [11].

The sample size was obtained calculating a margin of error of $5 \%$, a confidence level of $95 \%$, response distribution calculated in $50 \%$, with a population size of $3,075,646$, the minimum sample needed was 385 respondents. This information was obtained with the Raosoft ${ }^{\circledR}$ calculator sample size [12].

The survey was developed in the Neurocognitive and Neuropsychiatric Unit, Neurology Department, CEMIC University Hospital. The survey was divided into 6 Sections. A group of experts: neurologists, psychiatrists, and psychologists worked together to develop the queries for the survey. Neurologists developed Section A (General data) and Section B (Physical Health) queries. Psychiatrists and Psychologists developed Section C (Mental Health), Section D (Eating Habits), Section E (Hygienic Habits), and Section F (Daily Habits) queries. 
The survey was composed of 37 questions: 5 from section A, 12 from section B, 8 from section $C, 4$ from section $\mathrm{D}, 4$ from section $\mathrm{E}$, and 4 from section $\mathrm{F}$.

Section A. General data included the following variables: Age, Gender, Education, and whether respondents believed they belonged to the COVID-19 risk group or not ("The question was: Cree Usted que pertenece al grupo de riesgo para COVID-19? this translates as: Do you believe you belong to the COVID-19 risk group?). "If yes, please explain".

Section B. Physical Health Status was composed of the following variables: Presence or absence of any existing medical condition. Presence or absence of diabetes, if present: which type? Presence or absence of stroke. Presence or absence of seizures or epilepsy. Presence or absence of respiratory problems or illnesses. Presence or absence of other diseases and a description of them. Respondents were also asked about the appearance of new symptoms or an increase of existing symptoms in their condition.

Section C. Mental Health Status included the following variables: History of Depression, Background of Anxiety. The onset of Anxiety ("Since the start of the quarantine, do you consider yourself more anxious?" (No, I don't know, Yes, Maybe). Distress or Depression ("Since you have been in quarantine, do you consider yourself to be more irritable?"), Sleep Problems (“Are your sleep problems associated with quarantine?” and Irritability during quarantine (Since you have been in quarantine, do you consider yourself to be more irritable?).

Section D. Eating Habits included the following variables: Presence or Absence of Changes in Eating Habits during Isolation. Specification of Changes. Weight Gain during Isolation. Weight Loss during Isolation.

Section E. Hygiene Habits was composed of the following variables: Changes in Personal Hygiene Habits; Changes in Home Cleaning Habits; Do you consider these will be lasting changes?

$>$ Section F. Daily habits comprised the following variables: Smoking (presence or absence). How has isolation impacted smoking habits? Physical activity (presence or absence). How has isolation impacted the respondents' physical activity?

The survey was distributed by email, social media (Instagram \& Facebook), and WhatsApp. The response window was from April 12th, 2020 (3 weeks of SPCI) to June 5th, 2020 (11 weeks of SPCI).

The survey was anonymous and all data collected was destined to research purposes and to improve patient care. Participation in this survey was voluntary and informed consent was developed where it was understood that by answering it, the respondents accepted the use of the data for academic and healthcare purposes.

The local ethics committee at CEMIC University Hospital and the CEMIC Medical Department were consulted in March 2020, and the completion and distribution of this survey were approved. 


\section{Statistical analysis}

Descriptive statistics were reported based on survey results. Continuous data were expressed with their means and $\pm \mathrm{SD}$ (standard deviations). Categorical data were expressed in percentages and frequencies.

To analyze the sample it was divided into eight different age groups as follows:

1) 18 to 29 years,

2) 30 to 39 years,

3) 40 to 49 years,

4) 50 to 59 years,

5) 60 to 69 years,

6) 70 to 79 years,

7) 80 to 89 years,

8) more than 90 years.

Comparisons were done using the $\chi^{2}$ test and Monte Carlo (exact statistical test for small samples) for categorical variables across all age groups.

For the specific case of Section C: Mental Health Status (Continuous variables), the analysis was based on the Likert scale [13] assuming that the strength/intensity of an attitude is linear. We scored responses as follows:

- No: 0 points,

- I don't know: 1 point,

- Maybe: 2 points,

- Yes: 3 points.

Continuous variables represented in each age group were analyzed using the ANOVA test and Games Howell post hoc analyses.

Statistical significance established at $\mathrm{p}<0.05$, in two-tailed hypothesis tests The data were analyzed with the IBM SPSS Statistics 25 software.

\section{Results}

\subsection{General Data}

Four hundred and thirty-four (434) respondents answered the survey. Most respondents were female (75.8\%). Also, most had higher education (62.2\%) (Table 1). Overall, respondents were: $29.5 \%$ between 30 and 40 years old, and $51 \%$ between 40 and 70 years old (Table 1). A total of $34.8 \%$ of respondents believed they were part of the COVID-19 risk group. The answers given by the respondents about being part of the COVID-19 risk group were some of the following: age more than 60 years, concomitant diseases, dementia, cancer, neurological diseases (such as Parkinson, multiple sclerosis, stroke), hypertension, diabetes, respiratory disease, cardiac diseases, autoimmune disease, rheumatologic or autoimmune diseases, obesity, cigarette smoking. Twenty of the respondents answered that they were part of the medical system (n: 25, 5.7\%).

\subsection{Physical Health Status}

Thirty point eight percent $(30.8 \%, \mathrm{n}=134)$ had a pre-existing condition (hyper- 
tension (n: $80,18.4 \%$ ), diabetes (n: 18, 4.1\%), cardiac ischemia (n: 3, 0.7\%), stroke (n: $12,2.8 \%$ ), respiratory disease $(33,7.6 \%)$. Mostly of this preexisting condition were considered to be risk factors for severe cases of COVID-19, being Hypertension (18.4\%) the most frequent.

Other diseases reported by respondents are Alzheimer's Dementia (n: 12); Parkinson's Disease (n: 2), Multiple Sclerosis (n: 7), and Epilepsy (n: 6).

In the general sample, respondents in this Section did not report significant changes in the usual symptoms of their conditions (50.7\%).

Table 2 depicts the differences in the different age groups in the Preexisting condition, Hypertension (the most frequent preexisting condition), and changes in the usual symptoms of their conditions.

\subsection{Mental Health Status}

Background of anxiety and Depression showed that respondents had previous depressive symptoms in $19.6 \%$ of cases (n: 85 ), maybe in $13.4 \%$ (n: 58 ), don't know $3.5 \%$ (n: 15 ) and did not have in $61.8 \%$ (n: 268). In relation to anxiety symptoms, $42.9 \%$ (42.9\%) answered they had, $1.77 \%$ (n: 77$)$ maybe, $3 \%(13)$ they don't know and $34.1 \%$ (n: 148) did not have.

The onset of anxiety (n: 166, 38.2\%), depression symptoms (n: 121, 27.9\%), sleep disorders (n: 89, 20.5\%), and irritability (n: 118, 27.2\%) was reported during the isolation period Significant differences were observed between age groups $(\mathrm{p}<0.001)$ showing that the 30 - 39-year-old age group had more positive responses about anxiety (n: 62), depression symptoms (n: 38), sleep problems (n: 36 ) and irritability (n: 47 ); followed by the $40-49$ year age-old group.

Table 1. Section A. Demographic data.

\begin{tabular}{cccccccccc}
\hline \multicolumn{7}{c}{ Educational level } \\
\hline $\begin{array}{c}\text { Age } \\
\text { (years) }\end{array}$ & Frequency & Percentage & $\begin{array}{c}\text { Gender } \\
\text { Female/Male }\end{array}$ & $\begin{array}{c}\text { Primary } \\
\text { (complete) }\end{array}$ & $\begin{array}{c}\text { Primary } \\
\text { (incomplete) }\end{array}$ & $\begin{array}{c}\text { Secondary } \\
\text { (complete) }\end{array}$ & $\begin{array}{c}\text { Secondary } \\
\text { (incomplete) }\end{array}$ & Tertiary & University \\
\hline $18-29$ & 22 & 5.1 & $19(86 \%) / 3(14 \%)$ & $0(0 \%)$ & $0(0 \%)$ & $2(9 \%)$ & $2(9 \%)$ & $2(9 \%)$ & $16(73 \%)$ \\
$30-39$ & 128 & 29.5 & $102(80 \%) / 25(20 \%)$ & $1(1 \%)$ & $0(0 \%)$ & $7(5.5 \%)$ & $0(0 \%)$ & $24(19 \%)$ & $96(75 \%)$ \\
$40-49$ & 74 & 17.1 & $58(78 \%) / 16(22 \%)$ & $0(0 \%)$ & $0(0 \%)$ & $6(8.1 \%)$ & $0(0 \%)$ & $12(16 \%)$ & $56(76 \%)$ \\
$50-59$ & 75 & 17.3 & $59(78 \% / 16(22 \%)$ & $1(1 \%)$ & $1(1.3 \%)$ & $9(12 \%)$ & $2(3 \%)$ & $22(29 \%)$ & $40(54 \%)$ \\
$60-69$ & 74 & 17.1 & $54(73 \% / 20(27 \%)$ & $0(0 \%)$ & $1(1.4 \%)$ & $13(18 \%)$ & $0(0 \%)$ & $22(30 \%)$ & $38(51 \%)$ \\
$70-79$ & 41 & 9.4 & $28(68 \%) / 13(32 \%)$ & $1(2 \%)$ & $3(7 \%)$ & $8(20 \%)$ & $2(5 \%)$ & $10(24 \%)$ & $17(42 \%)$ \\
$80-89$ & 12 & 2.8 & $6(50 \%) / 6(50 \%)$ & $1(8 \%)$ & $0(0 \%)$ & $0(0 \%)$ & $4(33 \%)$ & $1(8 \%)$ & $6(51 \%)$ \\
over 90 & 2 & 0.5 & $2(100 \%) / 0(0 \%)$ & $1(50 \%)$ & $0(0 \%)$ & $1(50 \%)$ & $0(0 \%)$ & $0(0 \%)$ & $0(0 \%)$ \\
$\begin{array}{c}\text { Total } \\
\text { Cases }\end{array}$ & 428 & $98.6 \%$ & $329(75.8 \%) / 99(22.8 \%)$ & $5(1.2 \%)$ & $5(1.2 \%)$ & $46(10.6 \%)$ & $10(2.3 \%)$ & $93(21.4 \%)$ & $270(62.2 \%)$ \\
$\begin{array}{c}\text { Lost } \\
\text { cases }\end{array}$ & 6 & $1.4 \%$ & & & & & & &
\end{tabular}

Reference: In Argentina educational level is designed as follows: Primary school: seven years, Secondary school: five years, Tertiary: three years, University: duration depends on the degree pursued with an average of five years. 
Table 2. Section B. Physical Status. Differences between age groups in Hypertension and Changes in usual symptoms during isolation.

\begin{tabular}{cccccccccc}
\hline Age (years) & Frequency Hypertension & \multicolumn{7}{c}{$\begin{array}{c}\text { Changes in } \\
\text { usual } \\
\text { symptoms }\end{array}$} \\
\hline $18-29$ & 22 & No & $\begin{array}{c}\text { I don't } \\
\text { know }\end{array}$ & Yes & X2 (p) & $\begin{array}{c}\text { No } \\
\text { I don't } \\
\text { know }\end{array}$ & Yes & Maybe & X2 (p) \\
$30-39$ & 128 & $21(95.5 \%)$ & $1(4.5 \%)$ & $0(0 \%)$ & $7(31.8 \%)$ & $0(0 \%)$ & $0(0 \%)$ & $0(0 \%)$ \\
$40-49$ & 74 & $120(93.8 \%)$ & $1(0.8 \%)$ & $6(4.7 \%)$ & $56(43.8 \%)$ & $0(0 \%)$ & $3(2.3 \%)$ & $4(3.1 \%)$ \\
$50-59$ & 75 & $68(9.9 \%)$ & $1(1.4 \%)$ & $4(5.4 \%)$ & $38(51.4 \%)$ & $0(0 \%)$ & $4(5.4 \%)$ & $0(0 \%)$ \\
$60-69$ & 74 & $60(80 \%)$ & $1(1.3 \%)$ & $13(17.3 \%)$ & $<0.0001$ & $40(53.3 \%)$ & $1(1.3 \%)$ & $5(6.7 \%)$ & $1(1.3 \%)$ \\
$70-79$ & 41 & $41(55.4)$ & $0(0 \%=$ & $33(44.6 \%)$ & $44(59.5 \%)$ & $1(1.4 \%)$ & $0(0 \%)$ & $5(6.8 \%)$ \\
$80-89$ & 12 & $22(53.7 \%)$ & $0(0 \%)$ & $19(46.3 \%)$ & $29(70.7 \%)$ & $1(2.4 \%)$ & $3(7.3 \%)$ & $2(4.9 \%)$ \\
over 90 & 2 & $7(58.3 \%)$ & $1(8.3 \%)$ & $4(33.3 \%)$ & $6(50 \%)$ & $2(16.7 \%)$ & $0(0 \%)$ & $2(16.7 \%)$ \\
Total cases & 428 & $1(50 \%)$ & $0(0 \%)$ & $1(50 \%)$ & $0(0 \%)$ & $0(0 \%)$ & $1(50 \%)$ & $1(50 \%)$ \\
Lost cases & 6 & $341(78.6 \%)$ & $5(1.2 \%)$ & $80(18.4 \%)$ & $220(50.7 \%)$ & $5(1.2 \%)$ & $16(3.7 \%)$ & $15(3.5 \%)$ \\
\hline
\end{tabular}

Reference. Frequency and percentage (n/\%) are shown for each answer (No, I don't know, Yes an Maybe) to the questions about pre-existing conditions, hypertension and Changes in usual symptoms of preexisting conditions. X2 test was administered. Percentages are expressed for the total cases and for each age group case.

As mentioned above, Mental Health Status analysis was based on the Likert scale (13), assuming that the strength/intensity of an attitude is linear. We scored responses as follows: No: 0 points, I don't know: 1 point, Maybe: 2 points, Yes: 3 points. A descriptive analysis of these results in different age groups is shown in Table 3.

\subsection{Eating Habits}

Significant changes in eating habits were observed, with greater food consumption, especially more carbohydrates. Also, an increase in body weight was strongly reported (Table 4). Significant differences $(\mathrm{p}<0.001)$ were observed between the different age groups, showing that the 30 - 39-year-old age group had the largest number of changes in eating habits

\subsection{Personal Hygiene and House Cleaning Habits}

The results obtained show a significant improvement in personal hygiene and house cleaning habits (Table 4) and a large percentage of respondents believe that these will be lasting changes.

\subsection{Daily Habits}

A total of $80.2 \%$ of respondents were non-smokers, while $9.7 \%$ (42 respondents) smoked frequently. In the smoker subgroup, some quit smoking (n: 19; 4.4\%), and some smoked less (n: 20; 4.6\%). Physical Activity: 210 people (48.4\%) answered they did physical activity before social isolation started, on the other hand, $122(28.1 \%)$ did not exercise at all, and $98(22.6 \%)$ did so only occasionally. It 
was observed that despite social isolation, $39.6 \%$ of the cases ( $\mathrm{n}: 172)$ continued exercising and $8.5 \%$ (n: 37) started doing physical activities.

A descriptive analysis of daily habits in different age groups is shown in Table 5.

\section{Discussion}

COVID-19 pandemic leads populations to social, preventive, and compulsory isolation and lockdown measures, these have affected people's lives in different ways. In the present study, we developed a survey to study mental and physical health, hygienic, nutritional, and daily habits, in the general population of $\mathrm{Bu}-$ enos Aires city, during the quarantine period in COVID-19 pandemic.

Table 3. Section C. Mental Health. Onset of psychiatric symptoms during social isolation. ANOVA and post hoc test in different age groups.

\begin{tabular}{|c|c|c|c|c|c|c|c|c|c|c|c|}
\hline $\begin{array}{c}\text { Age } \\
\text { (years) }\end{array}$ & Anxiety & ANOVA & pos hoc & Depression & ANOVA & $\begin{array}{c}\text { Sleep } \\
\text { problems }\end{array}$ & ANOVA & post hoc & Irritability & ANOVA & post hoc \\
\hline $18-29$ & $1.73(1.4)$ & & & $1.59(1.2)$ & & 2.25 & & & $1.95(1.2)$ & & \\
\hline $30-39$ & $1.8(1.3)$ & & $\begin{array}{c}(30-39) \text { vs } \\
(70-79) \\
p<0.004\end{array}$ & $1.3(1.3)$ & & $1.4(1.4)$ & & $\begin{array}{c}(18-29) \text { vs } \\
(50-59) \\
p<0.04\end{array}$ & $1.3(1.3)$ & & $\begin{array}{c}(18-29) \text { vs } \\
(50-59) \\
p<0.04\end{array}$ \\
\hline $40-49$ & $1.9(1.3)$ & $\mathrm{P}<0.0001$ & $\begin{array}{c}(30-39) \text { vs } \\
(80-89) \\
\mathrm{p}<0.045\end{array}$ & $1.5(1.5)$ & $\begin{array}{c}\text { NS } \\
(p=0.12)\end{array}$ & $1.8(1.4)$ & $\mathrm{P}<0.015$ & $\begin{array}{c}(18-29) \text { vs } \\
(60-69) \\
p<0.024\end{array}$ & $1.39(1.3)$ & $\mathrm{p}<0.001$ & $\begin{array}{c}(18-29) \text { vs } \\
(70-79) \\
p<0.02\end{array}$ \\
\hline $50-59$ & $1.3(1.3)$ & & $\begin{array}{c}(40-49) \text { vs } \\
(70-79) \\
p<0.004\end{array}$ & $1.1(1.3)$ & & $1.5(1.4)$ & & $\begin{array}{c}(30-39) \text { vs } \\
(50-59) \\
p<0.03\end{array}$ & $0.9(1.2)$ & & $\begin{array}{c}(30-39) \text { vs } \\
(50-59) \\
p<0.03\end{array}$ \\
\hline $60-69$ & $1.4(1.3)$ & & $\begin{array}{c}(40-49) \text { vs } \\
(80-89) \\
\mathrm{p}<0.032\end{array}$ & $1.3(1.3)$ & & $1.1(1.4)$ & & $\begin{array}{c}(30-39) \text { vs } \\
(60-69) \\
p<0.029\end{array}$ & $1.2(1.3)$ & & $\begin{array}{c}(30-39) \text { vs } \\
(70-79) \\
p<0.03\end{array}$ \\
\hline $70-79$ & $0.9(1.3)$ & & & $0.9(1.2)$ & & $0.7(1.2)$ & & & $0.8(1.1)$ & & \\
\hline $80-89$ & $0.7(1.1)$ & & & $0.7(1.1)$ & & $0.8(0.9)$ & & & $0.9(1.29$ & & \\
\hline
\end{tabular}

Reference. Mean and standard deviation is shown in each variable (Anxiety, Depression, Sleep problems and Irritability. ANOVA and Games-Howell post hoc test were performed. NS: not significant.

Table 4. Section D. Eating habits. Changes in eating habits, weight loss or gain during social isolation. Section E - Hygienic Habits. Changes in hygienic habits during social isolation: personal hygiene, home cleaning, opinion about the duration of these changes (Will they be lasting?).

\begin{tabular}{ccccccc}
\hline Eating Habits & Total cases & Lost cases & No (n/\%) & I don't know (n/\%) & Yes (n/\%) & Maybe (n/\%) \\
\hline Change during isolation & 430 & 4 & $136 / 31.3 \%$ & $3 / 0.7 \%$ & $241 / 55.5 \%$ & $50 / 11.5 \%$ \\
Weight increase & 429 & 5 & $194 / 44.7 \%$ & $25 / 5.8 \%$ & $133 / 30.6 \%$ & $77 / 17.7$ \\
Weight Decrease & 406 & 28 & $316 / 72.8$ & $21 / 4.8 \%$ & $42 / 9.7$ & $27 / 6.2 \%$ \\
Hygienic Habits & & & & & $348 / 80.2 \%$ & $33 / 7.6 \%$ \\
Personal hygiene & 428 & 6 & $46 / 10.6 \%$ & $1 / 0.2 \%$ & $353 / 81.3 \%$ & $40 / 9.2 \%$ \\
Home hygiene & 429 & 5 & $32 / 7.4 \%$ & $4 / 0.9 \%$ & $167 / 38.5 \%$ & $157 / 36.2 \%$ \\
Believe Changes would last? & 385 & 49 & $41 / 9.4 \%$ & $20 / 4.6 \%$ & & \\
\hline
\end{tabular}

References: Frequency and percentage (n/\%) are shown for each response (No, I don't know, Yes) to the questions about changes in eating habits and weight loss or gain during the social isolation period. 
Table 5. Section F. Daily habits. Smoking and physical exercise, previous and during isolation period.

\begin{tabular}{|c|c|c|c|c|c|c|c|c|c|c|c|c|c|}
\hline & $\begin{array}{l}\text { Cigarette } \\
\text { Smoking }\end{array}$ & & & $\begin{array}{c}\text { Smoking } \\
\text { during } \\
\text { isolation }\end{array}$ & & & & $\begin{array}{l}\text { Physical } \\
\text { exercise }\end{array}$ & & & $\begin{array}{c}\text { Physical } \\
\text { exercise } \\
\text { during } \\
\text { isolation }\end{array}$ & & \\
\hline $\begin{array}{c}\text { Age } \\
\text { (years) }\end{array}$ & Occasionally & No & Yes & Quit & $\begin{array}{c}\text { As } \\
\text { always }\end{array}$ & More & Less & Sometimes & No & Yes & $\begin{array}{c}\text { Started } \\
\text { doing }\end{array}$ & No & Yes \\
\hline $18-29$ & $3(13.6 \%)$ & $\begin{array}{c}19 \\
(86.4 \%)\end{array}$ & $0(0 \%)$ & $3(13.6 \%)$ & $0(0 \%)$ & $0 \%)$ & $\begin{array}{c}2 \\
(9.1 \%)\end{array}$ & $9(4.9 \%)$ & $1(4.5 \%)$ & $12(5.5 \%)$ & $2(9.1 \%)$ & $7(31.8 \%)$ & $13(59.1 \%)$ \\
\hline $30-39$ & $17(13.3 \%)$ & $\begin{array}{c}93 \\
(72.2 \%)\end{array}$ & $\begin{array}{c}18 \\
(14.4 \%)\end{array}$ & $5(3.9 \%)$ & $\begin{array}{c}10 \\
(7.8 \%)\end{array}$ & $\begin{array}{c}10 \\
(7.8 \%)\end{array}$ & $9(7 \%)$ & $29(22.7 \%)$ & $\begin{array}{c}30 \\
(23.4 \%)\end{array}$ & $\begin{array}{c}69 \\
(53.9 \%)\end{array}$ & $13(10.2 \%)$ & $58(45.3 \%)$ & $53(41.4 \%)$ \\
\hline $40-49$ & $9(12.2 \%)$ & $\begin{array}{c}56 \\
(75.5 \%)\end{array}$ & $8(10.8 \%)$ & $6(8.1 \%)$ & $3(4.1 \%)$ & $4(5.4 \%)$ & $\begin{array}{c}4 \\
(5.4 \%)\end{array}$ & $12(16.2 \%)$ & $\begin{array}{c}28 \\
(37.8 \%)\end{array}$ & $\begin{array}{c}34 \\
(45.9 \%)\end{array}$ & $8(10.8 \%)$ & $37(50 \%)$ & $27(36.5 \%)$ \\
\hline $50-59$ & $1(1.3 \%)$ & $\begin{array}{c}65 \\
(86.7 \%)\end{array}$ & $9(12 \%)$ & $1(1.3 \%)$ & $6(8 \%)$ & $2(2.7 \%)$ & $\begin{array}{c}1 \\
(1.3 \%)\end{array}$ & $18(24 \%)$ & $21(28 \%)$ & $36(48 \%)$ & $7(9.3 \%)$ & $34(45.3 \%)$ & $30(40 \%)$ \\
\hline $60-69$ & $5(6.8 \%)$ & $\begin{array}{c}63 \\
(85.1 \%)\end{array}$ & $6(8.1 \%)$ & $3(4.1 \%)$ & $5(6.8 \%)$ & $1(1.4 \%)$ & $\begin{array}{c}3 \\
(4.1 \%)\end{array}$ & $19(25.7 \%)$ & $\begin{array}{c}24 \\
(32.4 \%)\end{array}$ & $\begin{array}{c}31 \\
(41.9 \%)\end{array}$ & $5(6.8 \%)$ & $41(55.4 \%)$ & $27(36.5 \%)$ \\
\hline $70-79$ & $2(4.9 \%)$ & $\begin{array}{c}37 \\
(90.2 \%)\end{array}$ & $0(0 \%)$ & $1(2.4 \%)$ & $1(2.4 \%)$ & $0(0 \%)$ & $0(0 \%)$ & $8819.5 \%)$ & $\begin{array}{c}11 \\
(26.8 \%)\end{array}$ & $\begin{array}{c}22 \\
(53.7 \%)\end{array}$ & $1(2.4 \%)$ & $21(51.2 \%)$ & $18(43.9 \%)$ \\
\hline $80-89$ & $0(0 \%)$ & $\begin{array}{c}11 \\
(91.7 \%)\end{array}$ & $1(8.3 \%)$ & $0(0 \%)$ & $0(0 \%)$ & $0(0 \%)$ & $0(0 \%)$ & $3(25 \%)$ & $6(50 \%)$ & $3(25 \%)$ & $1(8.3 \%)$ & $9(75 \%)$ & $2(16.7 \%)$ \\
\hline over 90 & $0(0 \%)$ & $2(100 \%)$ & $0(0 \%)$ & $0(0 \%)$ & $0(0 \%)$ & $0(0 \%)$ & $0(0 \%)$ & $0(0 \%)$ & $1(50 \% 9$ & $1(50 \%)$ & $0(0 \%)$ & $1(50 \%)$ & $1(50 \%)$ \\
\hline $\begin{array}{l}\text { Total } \\
\text { cases }\end{array}$ & $37(8.6 \%)$ & $\begin{array}{c}346 \\
(80.8 \%)\end{array}$ & $42(9.8 \%)$ & ) $19(4.4 \%)$ & $\begin{array}{c}26 \\
(6.1 \%)\end{array}$ & $17(4 \%)$ & $\begin{array}{c}20 \\
(4.7 \%)\end{array}$ & $98(22.9 \%)$ & $\begin{array}{c}122 \\
(28.5 \%)\end{array}$ & $\begin{array}{c}208 \\
(48.6 \%)\end{array}$ & $37(8.6 \%)$ & $208(48.6 \%)$ & $171(40 \%)$ \\
\hline
\end{tabular}

References. Frequency and percentage (n/\%) are shown for each answer (No, I don't know, Yes) to the questions about smoking habits and physical exercise previous and during isolation. Percentages are expressed for the total cases and for each age group case.

This survey aimed to observe and describe the physical and mental health status and possible changes in hygiene, food, and daily habits during the period of social isolation. The results helped us better understand the physical, mental, nutritional, and lifestyle situation of our people during these difficult times and implement adequate strategies to deal with the problems found.

In the present study, we were able to reach 434 respondents; more than 50\% were between 40 and 70 years old (51\%). Most respondents were female (75.8\%).

As $75.8 \%$ of respondents were female and these could probably indicate sampling bias, we searched for information about gender bias in a survey response. Some investigations of online survey response behavior suggest that women respond in greater proportions than men [14] [15] [16] [17]. Females are more likely to possess or value characteristics more consistent with connective selves, such as empathy or emotional closeness. Notably, some researchers maintain that females are more likely to engage in online activity characterized by communication and exchanging of information whereas males are more likely to engage in online activity characterized by seeking information [18]. Responding to an email by accessing an online survey, completing it, and returning it, is Online Survey Response Behaviour, certainly more a process of online information-exchange than it is a process of online information-seeking. From this 
standpoint, it is reasonable that higher response rates among female faculty than male faculty were observed [17] [18].

Most respondents had higher education (62.2\%). Thirty-four-point eight (34.8\%) percent of respondents considered themselves to be part of the COVID-19 risk group and fifteen point two (15.2\%) thought that maybe they were part of the risk group. Current criteria for being part of the COVID-19 risk group (in Argentina) include pregnancy, age (over 60 years old), respiratory diseases, immunosuppressed patients, diabetes, and heart diseases.

We reached the following conclusions. Firstly, almost $30 \%$ of the respondents (29.8\%) were more than 60 years old. Secondly, those respondents were well informed of such conditions and only $19 \%$ answered they did not know. This data can be sustained by the fact that almost $80 \%$ of the respondents seemed to know well whether they belonged to the risk group or not (34.8\% answered Yes; $44.2 \%$ answered No).

Regarding Physical status, thirty point eight percent $(30.8 \%, \mathrm{n}=134)$ had a pre-existing condition., Most of these preexisting conditions were considered to be risk factors for severe cases of COVID-19, being Hypertension (18.4\%) the most frequent. However, respondents in this section did not report significant changes in the usual symptoms of their conditions (50.7\%).

Regarding the Mental Health Status, anxiety, sleep problems, and irritability were significantly $(\mathrm{p}<0.05)$ observed mostly in the age groups: 30 - 39 years and 40 to 49 years. This important aspect should be addressed by physicians, psychologists, psychiatrists, and neurologists. One of the objectives of this survey was to detect these individuals, help them gain an awareness of those conditions, and encourage them to seek help should the need arise. Also, more specific surveys were performed by the Sleep Disorders Area of our Neurology Section and by the Psychiatric Department of our Hospital to deal with these issues.

Our study is in line with previous studies such as one developed by Qiu J, Shen B, Zhao M, et al. [1] that received 52,730 valid responses. Among all the respondents 18,599 were males $(35.27 \%)$ and 34,131 were females (64.73\%). Almost $35 \%$ of the respondents experienced psychological distress. Female respondents showed significantly higher psychological distress than their male counterparts. People under 18 years had the lowest Peritraumatic Distress Index (CPDI) scores mean and Individuals between 18 and 30 years of age or above 60 presented the highest CPDI scores [1].

In Italy, a study of COVID-19 pandemic and lockdown measures impact on mental health among the general population (N: 18147). The authors concluded that quarantine was associated with Posttraumatic stress (PTSD), depression, anxiety, insomnia [7].

A longitudinal study on the mental health during the COVID-19 epidemic in China [6] surveyed the general population twice, during the initial outbreak, and the epidemic's peak four weeks later, surveying demographics, symptoms, knowledge, concerns, and precautionary measures against COVID-19. There were 1738 respondents from 190 Chinese cities. Psychological impact and men- 
tal health status were assessed by the Impact of Event Scale-Revised (IES-R) and the Depression, Anxiety, and Stress Scale (DASS-21), respectively. This study [6] found that there was a statistically significant longitudinal reduction in mean IES-R scores after 4 weeks. Nevertheless, the mean IES-R score of the first- and second-survey respondents were above the cut-off scores. During the initial evaluation, moderate-to-severe stress, anxiety, and depression were noted in $8.1 \%, 28.8 \%$, and $16.5 \%$, respectively and there were no significant longitudinal changes in stress, anxiety, and depression levels. Protective factors included a high level of confidence in doctors, perceived survival likelihood, and low risk of contracting COVID-19, satisfaction with health information, personal precautionary measures.

Another longitudinal study was developed in the UK, evaluating Mental health before and during the COVID-19 pandemic [5]. Mental health was assessed using the 12-item General Health Questionnaire (GHQ-12). Repeated cross-sectional analyses were done to examine temporal trends, 17,452 participants in the COVID-19 web survey. Population prevalence of clinically significant levels of mental distress rose from 18.9\% (95\% CI 17.8 - 20.0) in 2018-19 to $27.3 \%$ (26.3 - 28.2) in April 2020, one month into UK lockdown. Mean GHQ-12 score also increased over this time, from 11.5 (95\% CI 11.3 - 11.6) in 2018-19, to $12.6(12.5$ - 12.8) in April 2020. Increases were greatest in 18 24-year-olds (2.69 points, 95\% CI 1.89 - 3.48), 25 - 34-year-olds (1.57, 0.96 $2.18)$, women $(0.92,0.50$ - 1.35), and people living with young children (1.45, 0.79 - 2.12). By late April 2020, mental health in the UK had deteriorated compared with pre-COVID-19 trends.

In a review and metanalyses [8] on the prevalence of stress, anxiety, depression among the general population during the COVID-19 pandemic, Nader Salady et al. (2020) found that prevalence of stress in 5 studies with a total sample size of 9074 was obtained as $29.6 \%$ (95\% confidence limit: 24.3 - 35.4), the prevalence of anxiety in 17 studies with a sample size of 63,439 as $31.9 \%$ (95\% confidence interval: 27.5 - 36.7), and the prevalence of depression in 14 studies with a sample size of 44,531 people as $33.7 \%$ (95\% confidence interval: 27.5 - 40.6).

Finally, another fact regarding emotional health status is that some of the respondents ( 25 respondents, $5.7 \%$ of the total sample) of this survey claimed to be part of the COVID-19 risk group as they belonged to the medical health system. In a sample of 1257 health care workers exposed to COVID-19 in China [19], depression symptoms were higher than any other such as distress, anxiety, and insomnia [19].

Eating habits: Significant changes in eating habits were observed, with higher amounts of food and carbohydrate consumption. Several respondents answered they thought to have gained weight during this period (Yes: 30.6\%, Maybe: $17.7 \%$ ). More surveys were developed and conducted by the Nutrition Department of our Hospital to investigate this issue.

Hygiene and Cleaning Habits: Significant improvements in personal hygiene 
and house cleaning habits were reported. Moreover, a large percentage of respondents believe that this will be a lasting change. This is a very positive aspect stemming from the difficult moment the whole world is going through.

As regards Daily Habits, some respondents quit smoking or smoking less. This is an interesting result. It might be expected that due to anxiety, smoking would have increased. These results could be considered as positive aspects.

An interesting observation was that, despite the isolation, respondents continued doing physical activity. Physical activity is very important to keep the mind calm, decrease anxiety and stress and it is a protective factor against vascular diseases (stroke, cardiac ischemia).

\section{Building resilience:}

"Building resilience requires planning and preparation based on assessments of risks, development of the capacity to restore functions quickly and effectively in the face of disruptions, and the capacity to adapt and change after a shock" [20] [21] [22].

The COVID-19 pandemic is an active course posing a huge challenge for humanity. People and societies should start building resilience to adapt to the constant changes and challenges this new world is posing for us [23].

\section{Strengths and Limitations of the Study}

Strengths: The greatest strength of the manuscript is being one of the first to assess mental and physical health, hygienic, nutritional, and daily habits during the social isolation in the city of Buenos Aires, Argentina.

Limitations: There are several limitations to this study to take into account. Firstly, the studied sample was a non-probability voluntary response sample (n: $434)$ of the general population (N: $3,075,646)$ of the city of Buenos Aires with a margin of error of $5 \%$, a confidence level of $95 \%$, and a response distribution calculated in 50\%; the results obtained should be considered with that. Secondly, the procedure to deliver the survey was by email, social media (Instagram \& Facebook), and WhatsApp. Therefore, people without access to these technological resources were not able to answer the survey. Thirdly, the fact that the data was obtained through a survey could mean there might be some biased results or several variables influenced by different situations or characteristics that are difficult to determine in a single survey. Fourthly, the emotional variables such as anxiety, depression, sleep problems and irritability studied were considered as possible symptoms the respondents could have, not as mental disorders. Finally, the survey was responded mostly by female respondents, this must be taken into consideration to analyze the final results, as it is demonstrated in various epidemiological studies that women are at a higher risk of depression [24]. Women are more vulnerable to stress and post-traumatic stress disorder than men [25]. In recent studies, the prevalence of anxiety and depression, and stress during the COVID-19 pandemic is shown to be higher in women than in men [1] [5] [6] [7] [8]. 


\section{Author Contributions}

$\mathrm{CD}$ and PPL authored the manuscript and discussed suggestions made by co-authors. DC and VG contributed to the conception of the work and co-authored the manuscript. CD, PPL, VG, AL, MF, MR, CP, JIR, SM, and MBV helped draft the work and contributed to its conception.

\section{Funding}

For this study, no funding was received from external sources.

\section{Acknowledgements}

Dr. Ricardo Valentini. Director del Departamento de Medicina. Hospital Universitario CEMIC, Buenos Aires, Argentina.

Fundación Norberto Quirno. Centro de Educación Medica e Investigaciones clínicas (CEMIC), Buenos Aires, Argentina.

Consejo Nacional de Investigaciones científicas y técnicas CONICET), Facultad de Ciencias Sociales, Universidad de Palermo (UP), Buenos Aires, Argentina.

\section{Conflicts of Interest}

The authors declare that the research was conducted in the absence of any commercial or financial relationships that could be construed as a potential conflict of interest.

\section{References}

[1] Qiu, J., Shen, B., Zhao, M., Wang, Z., Xie, B. and Xu, Y. (2020) A Nationwide Survey of Psychological Distress among Chinese People in the COVID-19 Epidemic: Implications and Policy Recommendations. General Psychiatry, 33, e100213. https://doi.org/10.1136/gpsych-2020-100213

[2] Paraguassu, L. and Mandl, C. (2020) Brazil Confirms First Coronavirus Case in Latin America.

https://www.reuters.com/article/us-china-health-brazil/brazil-test-confirms-first-co ronavirus-case-in-latin-america-source-idUSKCN20K1EU

[3] https://www.saude.gov.br

[4] https://www.argentina.gob.ar/coronavirus/informe-diario/julio2020

[5] Pierce, M., Hope, H., Ford, T., Hatch, S., Hotopf, M., John, A., Kontopantelis, E., Webb, R., Wessely, S., McManus, S. and Abel, K.M. (2020) Mental Health before and during the COVID-19 Pandemic: A Longitudinal Probability Sample Survey of the UK Population. The Lancet Psychiatry, 7, 883-892.

https://doi.org/10.1016/S2215-0366(20)30308-4

[6] Wang, C., Pan, R., Wan, X., Tan, Y., Xu, L., McIntyre, R.S., Choo, F.N., Tran, B., Ho, R., Sharma, V.K. and Ho, C. (2020) A Longitudinal Study on the Mental Health of General Population during the COVID-19 Epidemic in China. Brain, Behavior, and Immunity, 87, 40-48. https://doi.org/10.1016/j.bbi.2020.04.028

[7] Rossi, R., Socci, V., Talevi, D., Mensi, S., Niolu, C., Pacitti, F., Di Marco, A., Rossi, A., Siracusano, A. and Di Lorenzo, G. (2020) COVID-19 Pandemic and Lockdown Measures Impact on Mental Health among the General Population in Italy. Fron- 
tiers in Psychiatry, 11, 790. https://doi.org/10.3389/fpsyt.2020.00790

[8] Salari, N., Hosseinian-Far, A., Jalali, R., Vaisi-Raygani, A., Rasoulpoor, S., Mohammadi, M., Rasoulpoor, S. and Khaledi-Paveh, B. (2020) Prevalence of Stress, Anxiety, Depression among the General Population during the COVID-19 Pandemic: A Systematic Review and Meta-Analysis. Globalization and Health, 16, 57. https://doi.org/10.1186/s12992-020-00589-w

[9] Yates, D.S., Moore, D.S. and Starnes, D.S. (2008) The Practice of Statistics. 3rd Edition, W. H. Freeman, New York.

[10] http://www.observatorioamba.org/planes-y-proyectos/caba

[11] https://www.ign.gob.ar/NuestrasActividades/Geografia/DatosArgentina/Poblacion2

[12] http://www.raosoft.com/samplesize.html

[13] Likert, R. (1932) A Technique for Measurement Attitudes. American Journal of Sociology, 140, 55-65.

[14] Kwak, N. and Radler, B.A. (2002) Comparison between Mail and Web Surveys: Response Pattern, Respondent Profile, and Data Quality. Journal of Official Statistics, 18, 257-273.

[15] Saxon, D., Garratt, D., Gilroy, P. and Cairns, C. (2003) Collecting Data in the Information Age. Research in Education, 69, 51-66. https://doi.org/10.7227/RIE.69.5

[16] Smith, M.A. and Leigh, B. (1997) Virtual Subjects: Using the Internet as an Alternative Source of Subjects and Research Environment. Behavior Research Methods, Instruments, \& Computers, 29, 496-505. https://doi.org/10.3758/BF03210601

[17] Underwood, D., Kim, H. and Matier, M. (2000) To Mail or to Web: Comparisons of Survey Response Rates and Respondent Characteristics. 40 th Annual Forum of the Association for Institutional Research, Cincinnati, 21-24 May 2000, 21-24.

[18] Jackson, L.A., Ervin, K.S., Gardner, P.D. and Schmitt, N. (2001) Gender and the Internet: Women Communicating and Men Searching. Sex Roles, 44, 363.

https://doi.org/10.1023/A:1010937901821

[19] Lai, J., Ma, S., Wang, Y., Cai, Z., Hu, J., Wei, N., Wu, J., Du, H., Chen, T., Li, R., Tan, H., Kang, L., Yao, L., Huang, M., Wang, H., Wang, G., Liu, Z. and Hu, S. (2020) Factors Associated with Mental Health Outcomes among Health Care Workers Exposed to Coronavirus Disease 2019. JAMA Network Open, 3, e203976. https://doi.org/10.1001/jamanetworkopen.2020.3976

[20] Whitmee, S., Haines, A., Beyrer, C., Boltz, F., Capon, A.G., de Souza Dias, B.F., Ezeh, A., Frumkin, H., Gong, P., Head, P., Horton, R., Mace, G.M., Marten, R., Myers, S.S., Nishtar, S., Osofsky, S.A., Pattanayak, S.K., Pongsiri, M.J., Romanelli, C., Soucat, A., Yach, D., et al. (2015) Safeguarding Human Health in the Anthropocene Epoch: Report of the Rockefeller Foundation-Lancet Commission on Planetary Health. The Lancet (London, England), 386, 1973-2028. https://doi.org/10.1016/S0140-6736(15)60901-1

[21] Rodin, J. (2014) The Resilience Dividend: Being Strong in a World Where Things Go Wrong. Public Affairs, New York.

[22] Nelson, D.R., Adger, W.N. and Brown, K. (2007) Adaptation to Environmental Change: Contributions of a Resilience Framework. Annual Review of Environment and Resources, 32, 395-419.

https://doi.org/10.1146/annurev.energy.32.051807.090348

[23] Dillon, C. (2020) Emotional Health: From Science to the Whole Being. Cambridge Scholar Publishing, Cambridge. 
[24] Lim, G.Y., Tam, W.W., Lu, Y., Ho, C.S., Zhang, M.W. and Ho, R.C. (2018) Prevalence of Depression in the Community from 30 Countries between 1994 and 2014. Scientific Reports, 8, Article No. 2861. https://doi.org/10.1038/s41598-018-21243-X

[25] Sareen, J., Erickson, J., Medved, M.I., Asmundson, G.J., Enns, M.W., Stein, M., Leslie, W., Doupe, M. and Logsetty, S. (2013) Risk Factors for Post-Injury Mental Health Problems. Depression and Anxiety, 30, 321-327.

https://doi.org/10.1002/da.22077 